Review Article

\title{
Faulty ribosomes and human diseases: mistakes in "assembly line" going unnoticed ?
}

\author{
Anirban Chakraborty ${ }^{1} \&$ Indrani Karunasagar ${ }^{2}$ \\ ${ }^{1}$ Associate Professor, ${ }^{2}$ Professor \&Director (R\&D), ${ }^{2}$ Dean, ${ }^{1}$ Division of M olecular Genetics and Cancer \\ ${ }^{2}$ Faculty of Biological Sciences, Nitte University Centre for Science Education and Research, Nitte University, \\ M angalore, Karnataka, India. \\ Correspondence \\ Anirban Chakraborty \\ Associate Professor, Division of M olecular Genetics and Cancer, Nitte University Centre for Science Education and Research \\ Paneer Campus, M angalore - 575 018, Karnataka, India. \\ Mobile : +917022129624 E-mail : anirban@nitte.edu.in
}

\begin{abstract}
Ribosomes are molecular machineries that decode the information within mRNAs and generate all the proteins required for cellular activities. Ribosomes are essential to every living organism. The synthesis of ribosome is an intricate process, which is carried out in multiple steps throughout the cell in a highly coordinated fashion. For many years, the general perception was that any defects in the "ribosome assembly line" would have fatal consequences on cell. However, it has now become clear that production of defective ribosomes does not lead to lethality in human embryos. Rather, it manifests as specific disease conditions called ribosomopathies, which are rare genetic disorders affecting the bone marrow. This group of diseases has received considerable attention in recent years because of the mystery associated with them i.e. the tissue-specific nature of the clinical phenotypes despite the fact that the genes mutated in patients code for proteins that are absolutely essential and are housekeeping in nature. Despite considerable progress in understanding these diseases, it still remains unclear why defects in the production of a macromolecule as indispensable and as ubiquitous as the ribosome go unnoticed and why the effects are not universal but rather are restricted to specific cell types. This review is aimed at introducing the readers to important ribosomopathies with a brief description about the clinical symptoms, molecular genetics, and the treatmentsstrategies.
\end{abstract}

Key words: Ribosome, Ribosomopathies, Ribosomal Proteins, Inherited Bone M arrow Failure Syndromes, Anemia,

\section{Introduction}

The last step in the central dogma of molecular biology, i.e. the conversion of genetic information from messenger RNA (mRNA) into protein is carried out by ribosomes, the molecular machineries found in all cells. Ribosome is basically a protein/RNA complex,organized into two subunits, large and small, designated by their sedimentation coefficients. In eukaryotes, the larger subunit (60S) is composed of three species of ribosomal rRNA (rRNA; 28S, 5.8S, and 5S) and 47 different ribosomal

Access this article online Quick Response Code

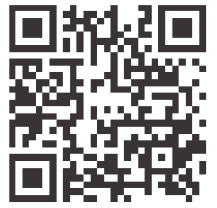
proteins (RPs) whereasthe smaller subunit (40S)is composed of a single species of rRNA (18S) and 32 different RPs ${ }^{1,2}$ (Figure 1).Although the numbers of rRNA species and RPs vary between eukaryotes and prokaryotes, the ribosomal components have been significantly conserved throughout the evolution ${ }^{3,4}$. Ribosome biogenesis is a major metabolic activity in cells and it requires a substantial amount of cellular energy ${ }^{5}$. The rate of ribosome production is directly linked to growth and proliferation, two closely connected events in a cell. During favorable stimuli, cells induce ribosome production because growing cells require more proteins whereas in stress situations, cells downregulate ribosome production to reduce protein synthesis. Thus, the ribosome activity is well balanced in normal cells and loss of this balance may lead to deregulated cell growth as seen in cancer. Indeed, star oncoprotein and tumor suppressor genes namely cM yc and p53, which are frequently mutated in cancers, are known regulators of ribosome biogenesis ${ }^{6}$.

\section{The process of ribosome synthesis}

The synthesis of the ribosome is a tightly regulated sequential chain of events that begins in the nucleolus and 
ends in the cytoplasm? ${ }^{7}$. During this process, many cofactors or accessory proteins(remodeling factors, transcription factors, processing factors, export factors and assembly factors) and small noncoding RNAs (snoRNAs)attach with and dissociate from the preassembled particles at various steps, to finally form the mature rRNA-RP complex. The process is very similar to an "assembly line" of a car where different parts are brought together in a sequential manner to make the final product ${ }^{8}$. Although ribosome biogenesis continues throughout the cell, the majority occurs within the nucleolus, the most conspicuous organelle inside the nucleus. The nucleolus is a transient structurethat assembles around the ribosomal DNA (rDNA) repeats during telophase and disassembles during mitosis phase of cell cycle ${ }^{9}$. A mammalian nucleolus has three morphologically distinct sub-compartments: the fibrillar centre ( $F C$ ), the dense fibrillar centre (DFC), and the granular component (GC). ${ }^{9}$ The first step in ribosome biogenesis is the transcription of rDNA repeats into a single pre-rRNA precursor (47S) by RNA polymerase (Pol) I in the FCs.This pre-RNA precursor is then cleaved and modified by several accessory proteins and snoRNAs within the DFCs to form three species of rRNA (18S, 5.8S, and 28S). Pol III transcribes the fourth species, the 5S rRNA and Pol II transcribes the protein components of the ribosome, the RPs, separately in the nucleoplasm. The 5S rRNA and the RPs are imported within the nucleolus, and assembled with other rRNAspecies in the GCs to form the small (40S) and the large (60S) subunits. These pre-assembled particles are then exported to the cytoplasm, where additional maturation occurs to finally yield the mature (80S) ribosome ${ }^{9,10}$ (Figure 2).

\section{Human pathologies associated with defects in ribosome synthesis}

In the last two decades, there has been a paradigm shift in our understanding of the ribosomes. In the past, the accepted notion was that the ribosomes are absolutely essential for cells and hence any mistakes in ribosome biogenesis would directly affectembryonic viability. However, several path-breaking findings have changed this perception and it has now become clear that production of faulty ribosomes does not necessarily lead to lethal effects in humans. Instead, it manifests as rare genetic diseases, mostly inherited.These diseases collectively referred to as "Ribosomopathies", result from mutations in genes encoding either ribosomal proteins or ribosome biogenesis associated factors ${ }^{11}$. The majority of these diseases exhibit tissue-specific phenotypes, most often involving the hematopoietic components of the bone marrow. Interestingly, they are also associated with an increased risk of developing cancer. Other associated pleiotropic anomalies include growth retardation, craniofacial abnormalities, and physical deformities. The literature cites a large number of diseases under this category and describing all of them is not within the purview of this article. Moreover, the role of ribosome or ribosomal components in the clinical manifestation is not clear for many of these diseases. The review by Freed et al $(2010)^{12}$ describes the ribosomal diseases in a comprehensive manner. Here we have focused on the most important ones, particularly those in which the ribosomal components have been clearly demonstrated as the causative agents (Table 1) and where the molecular mechanisms underlying the disease pathogenesis have been explored through functional studies in yeast, mice and zebrafish models.

\section{Diamond Blackfan Anemia (DBA, OM IM \#105650)}

DBA is a rare congenital disease characterized by red cell aplasia that presents with severe anaemia in early infancy, usually within the first six months of age. Approximately $50 \%$ of the patients exhibit physical anomalies such as craniofacial deformities and thumb abnormalities, including the classical triphalangeal thumb and cleft lip and/or palate. The disease is also associated with an increased risk of cancer, such as acute myeloid leukemia, osteogenic sarcoma, and other solid organ cancers. The classical presentation of DBA includes a usually macrocytic, or occasionally normocytic, anemia with reticulocytopenia, near normal or variable neutrophil and platelet counts and a normocellular bone marrow (BM) with a paucity of erythroid precursors, in a child less than one year ${ }^{13}$. These clinical diagnostic criteria are usually supported by 
mutation analysis of "known DBA genes". DBA is caused by mutations in either small or large subunit-associated RP genes, which are the structural components of ribosome. M utationsin a single allele are sufficient for the disease to precipitate, indicating haploinsufficiency of the encoded ribosomal proteins. At present, mutations have been identified in 16 RP genes with RPS19 being the most frequently mutated gene in DBA patients (in $25 \%$ of the patients) ${ }^{7}$. However, while known RP mutations now account for approximately half of DBA cases, the genes mutated in the other half of DBA patients remain unknown. The pathophysiology of DBA has been studied quite extensively in a variety of animal models and several interesting hypotheses have been proposed ${ }^{6}$. A p53dependent apoptotic pathway, presumably resulting in erythroid cell death, appears to be the most commonly accepted pathophysiology mechanism ${ }^{6}$. However, it is still uncertain why p53 would target only the erythroid cells, while allowing other cells to grow. The current mainstays of treatment include red cell transfusions and iron chelation, corticosteroids, and hematopoietic stem cell transplantation (HSCT) $)^{14}$.

\section{Shwachman Diamond Syndrome (SDS, OM IM \#260400)}

SDS is a rare autosomal recessive disease characterized by bone marrow dysfunction (variable cellularity), exocrine pancreatic insufficiency and an increased risk for myelodysplasia and acute myelogenous leukemia (AM L). Neutropenia is a hallmark of the bone marrow failure in SDS. However, reticulocytopenia and thrombocytopenia are also frequently observed in the patients. Other clinical features include skeletal abnormalties, cardiac malfunction, immunological deficiencies, and hepatomegaly with elevated levels of liver enzymes ${ }^{15}$. Approximately $90 \%$ of the patients have biallellic mutations in the ShwachmanBodian-Diamond Sydrome (SBDS) gene ${ }^{16}$. Homozygous deletion of SBDS in mice results in embryonic lethality, indicating that it is an essential gene ${ }^{17}$. Although studies in yeast and mammalian models have shown that SBDS is essential for ribosome biogenesis ${ }^{18,19}$, the exact role of this gene was understood only recently from the work of Finch et $\mathrm{al}^{20}$ who have shown that SBDS is required for promoting the release of eukaryotic initiation factor 6 (elF6) from the 605 subunit. elF6 keeps the 605 subunit in a functionally inactive state and must be removed before the large subunit (605) can join the small subunit to initiate translation. However, despite these elegant findings, it still remains unclear how ribosomal malfunction specifically affects the pancreas and the bone marrow in patients with SDS. Therapeutic strategies include transfusions, oral pancreatic enzyme supplementation, antibiotics and granulocyte colony stimulating factor. However, the only definitive therapy is $\mathrm{HSCT}^{15}$.

\section{X-linked Dyskeratosis Congenita (X-DC, OM IM \#305000)}

$X-D C$ is a recessive condition associated with the simultaneous presence of abnormal skin pigmentation, nail dystrophy, and mucosal leukoplakia (main mucocutaneous triad). M ore than $80 \%$ of the patients have pancytopenia due to BM failure. Additional clinical features includepulmonary fibrosis, and very high risk of cancer, particularly $A M L^{21}$. The $X$-DC patients harbor mutations in the DKCl gene, which encodes Dyskerin, a nucleolar protein ${ }^{22}$. Dyskerin associates with box H/ACA snoRNPs to catalyze post-transcriptional modification (pseudouridylation) of rRNAs ${ }^{23}$. Dyskerin is also a member of the telomerase complex that is responsible for maintaining telomere length ${ }^{24} . X-D C$ patients usually have shortened telomeres and assessment of telomere length is often necessary to confirm the clinical diagnosis of $X-D^{22}$. However, X-DC patients with normal telomere length have also been identified ${ }^{25}$. Thus, at present $X-D C$ is considered a disease of defective rRNA processing and defective telomere disorder. X-DC patients display impaired translation of p53 mRNA resulting in reduced p53 expression, thus providing a basis for their increased susceptibility to cancer $^{26}$. Since majority of the patients exhibit severe BM failure, BM transplant is the most definitive treatment strategy available. Recently, the use of induced pluoripotent stem (iPS) cellhas shown promise as an alternative therapeutic strategy ${ }^{27}$.

\section{5qDeletion Syndrome (5q; O M IM \#153550)}

$5 q$ syndrome is an acquired myelodysplastic (MDS) disorder characterized by macrocytic anemia, normal or elevated platelet count, and erythroid hypoplasia and hypolobulated megakaryocytes in the bone marrow ${ }^{28}$. The 
patients usually have a deletion in the long arm of the chromosome 5, which results in the loss of 40 genes $^{29}$. The erythroid phenotype in the patients, which closely resembles DBA, is caused by mutation in RPS14 gene that is located in the common deleted region and a member of the small subunit of the ribosome $\mathrm{e}^{30}$. Interestingly, the other hematological phenotypes such as elevated platelet counts and defective megakaryocytes are caused by the loss of two microRNAs, namely miR-145 and miR-146a ${ }^{31}$, which are also transcribed from the same deleted region of chromosome 5. The standard treatment strategies include use of immunomodulatory drugs such as lenalidomide. As for any MDS disorders, $5 q$ patients also have a risk of AM L. However, those who respond well to lenalidomide have a low risk of $A M L$ whereas in the non-responders, the risk is substantially higher.

\section{Treacher Collins Syndrome 1 (TCS, OM IM \#154500)}

TCS is an autosomal dominant condition characterized by craniofacial disorders affecting face, ears, eyes and mouth. The clinical features include antimongoloid slant of the eyes, coloboma of the lid, micrognathia, microtia, hypoplastic zygomatic arches, and macrostomia ${ }^{32}$. TCS is caused by heterozygous mutations in TCOF1, which encodes Treacle, a nucleolar protein involved in transcription of rDNA and methylation of 18SrRNA ${ }^{33,34}$. TCS patients are not predisposed to any form of tumors. Treatment planning generally involves a comprehensive staged reconstructive approach ${ }^{35}$.

\section{Isolated Congenital Asplenia (ICA, OM IM \#271400)}

ICA is an autosomal dominant condition characterized by the absence of spleen at birth without any other developmental defects ${ }^{36}$. It is a life-threatening condition due to recurrent severe and invasive microbial infections, particularly by Streptococcus pneumoniae. The disease is caused by mutations in the RPSA gene, which encodes ribosomal protein $\mathrm{SA}$, a component of the small subunit of ribosome ${ }^{37}$. The treatment strategies include antibiotic prophylaxis (transient or lifelong), immunization at the recommended age, especially against encapsulated bacteria, efficient management of suspected infection, and most importantly, parent education explaining the risks involved.

\section{North American Indian Childhood Cirrhosis (NAIC, OM IM \#604901)}

NAIC is an autosomal recessive intrahepatic cholestasis first described in Ojibway-Cree children from northwestern Quebec. It typically presents with neonatal jaundice in an otherwise healthy child and progresses to biliary cirrhosis. The disease is caused by a homozygous mutation (a missense mutation; R565W) in the hUT4/Cirhin, which is encoded by $\mathrm{CIRH} 1 \mathrm{~A}^{38}$. hUTP4/Cirhin along with UTP15 and WDR43are the core components of t-UTP subcomplex. tUTPis a member of the small subunit (SSU) processome, which is involved in the processing of 18SrRNA in human ${ }^{39}$. Liver transplantation is the only definitive therapy for this disease ${ }^{40}$.

\section{Conclusion and Future Perspectives}

The discovery of ribosomopathies and the tissue-specific manifestation of these diseases has made it very clear that the outcome of ribosomal defects is not uniform, but variable in different tissues. Several hypotheses have been proposed to explain this tissue specificity, however, the exact mechanisms are yet to be defined ${ }^{41}$. Although highly speculative, recent evidence seem to suggest that cells might possess "specialized ribosomes", ribosomes that are heterogeneous in their composition and vary in different cell types ${ }^{42}$. For example, loss of Rpl38 in mice does not affect global translation, but specifically alters translation of a subset of mRNAs that encode homeobox genes ${ }^{43}$. Thus, it is conceivable that cells have "ribosome code" where the individual components of the ribosomes influence translation of specific mRNAs in a tissue-specific manner. A challenge for future will be to prove this hypothesis and to identify these mRNAs. In addition, functional studies in integrated model systems will be crucial in designing effective diagnostic and treatment strategies for human ribosomopathies. 


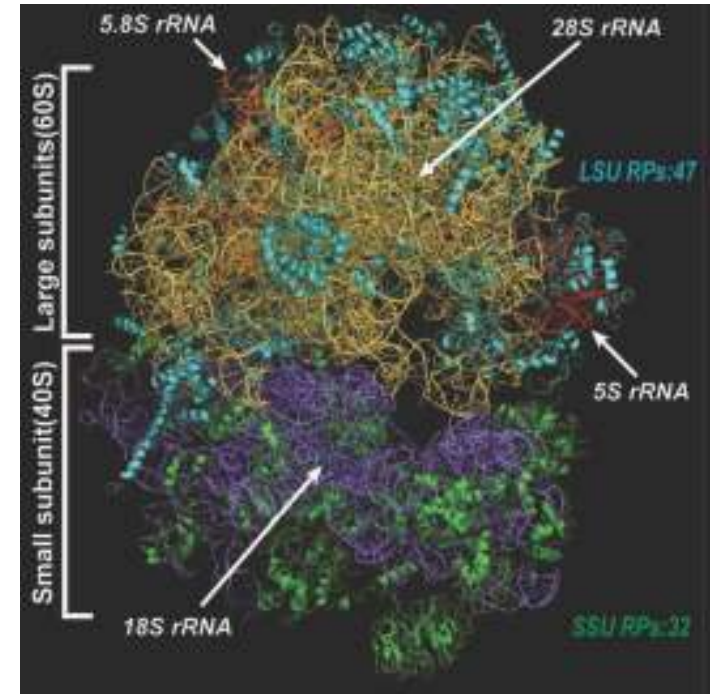

Fig. 1 : Crystal structure of the eukaryotic ribosome (80S) [PDBID: 4V7R (Ben-Shem et al, 2010, Science 330: 1203-1209]. The figure was generated using PyM OL software (The PyMOL Molecular Graphics System, Version 1.1r2pre, DeLano Scientific LLC.).

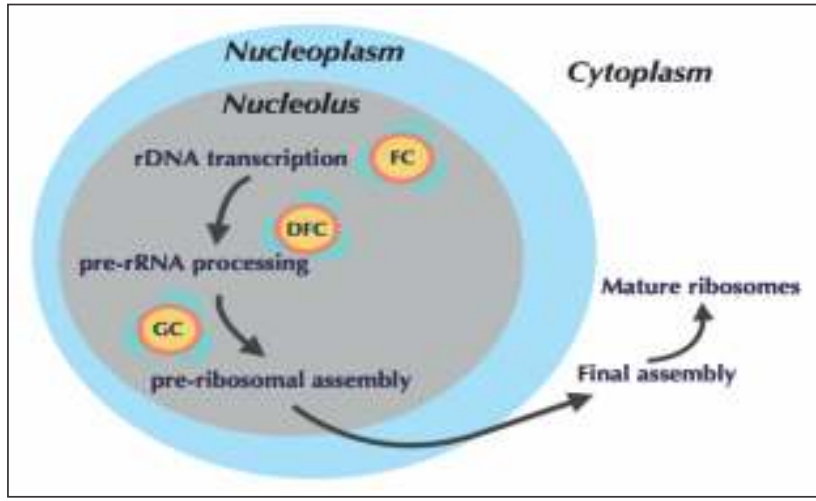

Fig. 2 : A simplifiedschematic representation of the process of ribosome biogenesis. See text for details. FC: Fibrillar Centre, DFC: Dense Fibrillar Centre, GC: Granular Component.

Table 1 : M ajor Ribosomopathies in Human

\begin{tabular}{|l|l|l|l|}
\hline Disease & Mutated Gene & Tissue-specific phenotype & Ribosomal effects \\
\hline $\begin{array}{l}\text { Diamond-Blackfan } \\
\text { anemia (DBA) }\end{array}$ & $\begin{array}{l}\text { RPS19 and fifteen other RP } \\
\text { genes }\end{array}$ & Red cell aplasia & $\begin{array}{l}\text { Impaired 40S and } \\
60 S \text { biogenesis }\end{array}$ \\
\hline $\begin{array}{l}\text { Shwachman Diamond } \\
\text { Syndrome (SDS) }\end{array}$ & SBDS & $\begin{array}{l}\text { Neutropenia, Exocrine } \\
\text { pancreatic insufficiency }\end{array}$ & $\begin{array}{l}\text { Impaired maturation } \\
\text { of 60S subunit }\end{array}$ \\
\hline $\begin{array}{l}\text { X linked dyskeratosis } \\
\text { congenita (X-DC) }\end{array}$ & DKC1 & $\begin{array}{l}\text { Mucocutaneous triad (abnormal } \\
\text { skin pigmentation, nail dystrophy, } \\
\text { and mucosal leukoplakia) }\end{array}$ & $\begin{array}{l}\text { Impaired posttranscriptional } \\
\text { modification of rRNA }\end{array}$ \\
\hline $\begin{array}{l}\text { 5qdeletion syndrome (5q) } \\
\text { (2) }\end{array}$ & RPS14, miR-145, miR-146a & $\begin{array}{l}\text { Macrocytic anemia, Normal or } \\
\text { high platelet count, Hypolobulated } \\
\text { megakaryocytes }\end{array}$ & $\begin{array}{l}\text { Defective 18SrRNA } \\
\text { processing, 40S } \\
\text { subunit deficiency }\end{array}$ \\
\hline $\begin{array}{l}\text { Treacher Collins } \\
\text { syndrome 1 (TCS) }\end{array}$ & TCOF1 & $\begin{array}{l}\text { Impaired rRNA } \\
\text { transcription }\end{array}$ \\
\hline $\begin{array}{l}\text { Isolated Congenital } \\
\text { Asplenia (ICA) }\end{array}$ & RPSA & Absence of spleen & Impaired 40S biogenesis \\
\hline $\begin{array}{l}\text { North American Indian } \\
\text { Childhood Cirrhosis (NAIC) }\end{array}$ & CIRH1A & Biliary cirrhosis & Defective 18SrRNA processing \\
\hline
\end{tabular}

\section{Acknowledgements}

We would like to thank Dr. Junichi Iwakiri, Department of Computational Biology and Medical Sciences, The University of Tokyo, Japan for helping us with the crystal structure of eukaryotic ribosome. Our heartfelt gratitude

\section{References}

1. Wool IG. The structure and function of eukaryotic ribosomes. Ann Rev Biochem1979; 48:719- 754.

2. Chakraborty A, Kenmochi N. Ribosomes and ribosomal proteins: More than just 'housekeeping' Els In: eLS. Chichester: John Wiley \& Sons, Ltd; 2012.

3. http://rdp.cme.msu.edu/ index.jsp (accessed August 11, 2015).

4. http://ribosome.med.miyazaki-u.ac.jp (accessed August 11, 2015). to Nitte University for providing the resources and infrastructure to continue research related to human health and disease at the new campus in Paneer, Mangalore.

5. Warner JR. The economics of ribosome biosynthesis in yeast. Trends Biochem Sci1999; 24:437-440.

6. Chakraborty A, Uechi T, Kenmochi N. Guarding the translation apparatus: defective ribosome biogenesis and the p53 signaling pathway. Wiley Interdisciplinary Reviews: RNA 2011; 2:507-522.

7. Thomson E, Sebastien F-C, Hurt Ed. Eukaryotic ribosome biogenesis at a glance.J Cell Science 2013; 126:4815-4821. 
8. https://cmns.umd.edu/news-events/news/1999 (accessed August 11, 2015)

9. Lam YW, Trinkle-M ulcahy L, Lamond Al. The nucleolus. J Cell Science 2005; 118:1335-1337.

10. EmmottE, HiscoxJA. Nucleolar targeting: the hub of the matter. EM BO Reports 2009; 10: 231-238.

11. Narla A, Ebert BL. Ribosomopathies: human disorders of ribosome dysfunction. Blood2010; 115:3196- 3205.

12. Freed EF, Bleichert F, Dutca LM, Baserga SJ. When ribosomes gobad: diseases of ribosome biogenesis. Mol Biosys 2010; 6:481-493.

13. Vlachos A, Ball S, Dahl N, Alter BP, Sheth S, Ramenghi U, et al. Diagnosing and treating Diamond Blackfan anemia: results of an international clinical consensus conference. $\mathrm{Br} J$ Haematol 2008; 142:859-876.

14. Vlachos A, M uir E. How I treat Diamond Blackfan anemia. Blood 2010; 116: 3715-3723.

15. Burroughs L, Woolfrey A, Shimamura A. Shwachman Diamond Syndrome- a review of the clinical presentation, molecular pathogenesis, diagnosis, and treatment. Hematol Oncol Clin North Am 2009; $23: 233-248$

16. Johnson AW, Ellis SR. Of Blood, bones, and ribosomes: is SwachmanDiamond syndrome a ribosomopathy? Genes and Development 2011; 25: 898-900

17. Zhang S, Shi M, Hui CC, Rommens JM. Loss of the mouse ortholog of the shwachman-diamond syndrome gene (Sbds) results in early embryonic lethality. M ol Cell Biol 2006; 26: 6656- 6663.

18. Moore JB IV, Farrar JE, Arceci RJ, Liu JM, Ellis SR. Distinct ribosome maturation defects in yeast models of Diamond- Blackfan anemia and Shwachman-Diamond syndrome. Haematologica 2010; 95: 57-64.

19. Austin KM, Leary RJ, Shimamura A. The Shwachman- Diamond SBDS protein localizes to the nucleolus. Blood 2005; 106: 1253-1258.

20. Finch AJ, Hilcenko C, Basse N, Drynan LF, Goyenechea B, M enne TF, et al. Uncoupling of GTP hydrolysis from elF6 release on the ribosome causes Shwachman-Diamond syndrome. Genes and Development 2011; 25: 917-29.

21. Dokal I. Dyskeratosis Congenita. Hematology The American Society of Hematology Education Program Book 1: 2011; 480-486.

22. Heiss NS, Knight SW, Vulliamy TJ, Klauck SM, Wiemann S, M ason PJ, et al. X-linked dyskeratosis congenita is caused by mutations in a highly conserved gene with putative nucleolar functions. Nat Genet1998; 19:32-38.

23. Yoon A, Peng G, Brandenburg Y, Zollo O, Xu W, Rego E, et al. Impaired control of IRES- mediated translation in X-linked dyskeratosis congenita. Science2006; 312:902-906.

24. Calado RT, Young NS. Telomere maintenance and human bone marrow failure. Blood 2008; 111:4446 - 4455

25. Nelson ND, Bertuch AA. Dyskeratosis congenital as a disorder of telomere maintenance. Mut Res 2012; 730: 43-51.

26. M ontanaro L, Calieni M, Bertoni S, Rocchi L, Sansone P, Storci G, et al. Novel dyskerin-mediated mechanism of p53 inactivation through defective mRNA translation. Cancer Res2010; 70:4767 - 4777.
27. Suneet A, Loh Y-H, M CLoughlin EM, Huang J, Park I-H, M iller JD, et al. Telomere elongation in induced pluripotent stem cells from dyskeratosis congenita patients. Nature 2010; 464: 292-296.

28. Van den Berghe H, Cassiman J, David G, Fryns JP, M ichaux JL, Sokal G. Distinct hematological disorder with deletion of long arm of no. 5 chromosome. Nature 1974; 251:437-438.

29. Boultwood J, Fidler C, Strickson AJ, Watkins F, Gama S, Kearney L, et al. Narrowing and genomic annotation of the commonly deleted region of the $5 q$ syndrome. Blood2002; 99:4638-4641.

30. Ebert BL, Pretz J, Bosco J, Chang CY, Tamayo P, Galili N, et al. Identification of RPS14 as a $5 q$ syndrome gene by RNA interference screen. Nature2008; 451:335 - 339

31. Starczynowski DT, Kuchenbauer F, Argiropoulus B, Sung S, M orin R, M uranyi $A$, et al. Identification of miR-145 and miR-146a as mediators of the $5 q$ syndrome phenotype. Nat M ed2010; 16:49-58.

32. Dixon MJ. Treacher Collins syndrome. Hum M ol Genet 1996; 5:13911396.

33. Valdez BC, Henning D, So RB, Dixon J, Dixon MJ. The Treacher Collins syndrome (TCOF1) gene product is involved in ribosomal rDNA gene transcription by interacting with upstream binding factor. Proc Natl Acad SciUSA2004; 101:10709-10714.

34. Gonzales B, Henning D, So RB, Dixon J, Dixon MJ, Valdez BC. The Treacher Collins syndrome (TCOF1) gene product is involved in prerRNA methylation. Hum M ol Genet2005; 14:2035-2043.

35. Posnick JC, Ruiz RL. Treacher Collins syndrome: current evaluation, treatment, and future directions. Cleft Palate CraniofacialJ2000; $37: 434$

36. Mahlaoui N, M inard-Colin V, Picard C, Bolze A, Ku C-L, Tournilhac O, et al. Isolated congenital asplenia: a French nationwide retrospective survey of 20 cases. J. Pediat 2011;158: 142-148.

37. Bolze A, Mahlaoui N, Byun M, Turner B, Trede N, Ellis SR, et al. Ribosomal protein SA haploinsufficiency in humans with isolated congenital asplenia. Science 2013; 340: 976-978.

38. Chagnon P, M ichaud J, M itchell G, M ercier J, M arion J, Drouin E, et al. A missense mutation (R565W) in cirhin (FL)14728) in North American Indian childhood cirrhosis. Am J Hum Genet 2002; 71: 1443-1449.

39. Wada K, Sato M , Araki N, Kumeta M , Hirai Y, Takeyasu K, et al. Dynamics of WD-repeat containing proteins in SSU processome components. Biochem Cell Biol 2014; 92: 191-199.

40. Betard C, Rasquin-Weber A, Brewer C, Drouin E, Clark S, Verner A, et al. Localization of a recessive gene for North American Indian childhood cirrhosis to chromosome region 16q22-and identification of a shared haplotype. AmJ Hum Genet 2000; 67: 222-228.

41. M cCann KL, Baserga SJ. Mysterious Ribosomopathies. Science 2013; 341: 849-850.

42. Xue S, Barna M. Specialized ribosomes: a new frontier in gene regulation and organismal biology. Nature Reviews: M ol Cell Biol 2012; 13: 355-369

43. Kondrashov N, Pusic A, Stumpf CR, Shimizu K, Hsieh AC, Xue S, et al. Ribosome-mediated specificity in Hox mRNA translation and vertebrate tissue patterning. Cell 2011; 145, 383-397. 